Revisión de TEMA

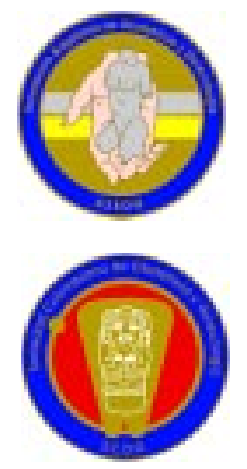

\title{
EMPLEO DE METRONIDAZOL DURANTE EL PRIMER TRIMESTRE DE EMBARAZO: REVISIÓN BIBLIOGRÁFICA
}

METRONIDAZOLE UISE DUIRING THE FIRST

TRIMIESTER OF PREGNANCY: A REVIIEW

Ralph Parrado, M.D.*

Recibido: septiembre 2/2002 - Revisado: octubre 14/2002 - Aceptado: noviembre 30/2002

\section{RESUMEN}

Antecedentes: el metronidazol se emplea en la paciente obstétrica cada día con mayor frecuencia debido a las complicaciones obstétricas asociadas a la vaginosis bacteriana y la tricomoniasis. Existen, sin embargo, médicos y mujeres que todavía dudan emplear el metronidazol, especialmente durante los primeros meses de embarazo por temor a posibles efectos teratogénicos. Objetivo: evaluar el riesgo de teratogenicidad del metronidazol durante el primer trimestre de embarazo. Método: revisión de la literatura actual sobre el empleo de metronidazol durante el primer trimestre de embarazo y sus efectos teratogénicos. Conclusiones: la administración de metronidazol durante el primer trimestre de embarazo no se relaciona clínicamente con un mayor riesgo de alteraciones congénitas.

Palabras clave: metronidazol, embarazo, teratogenicidad.

\footnotetext{
Director Médico

Sede Santa Isabel - Fundación Oriéntame

Bogotá, D.C.
}

\section{SUMMARY}

Background: Metronidazole is used extensively in the obstetric patient due to the obstetric complications associated to bacterial vaginosis and trichomoniasis. However, physicians and patients alike hesitate to use metronidazole, especially during the first months of pregnancy fearing possible teratogenic effects. Objective: To evaluate teratogenic risk of metronidazole during the first trimester of pregnancy. Method: Review of medical literature on metronidazole use during the first trimester of pregnancy and its teratogenic effects. Conclusion: Metronidazole exposure during the first trimester of pregnancy does not appear to increase the risk of overall birth defect occurrence.

Key words: metronidazole, pregnancy, teratogenicity.

\section{INTRODUCCIÓN}

El metronidazol es un derivado sintético del nitroimidazol que se emplea en el tratamiento de la tricomoniasis, la vaginosis bacteriana y otras infecciones causadas por protozoarios y microorganismos anaerobios. ${ }^{1-3}$ Durante años se ha considerado un medicamento seguro con muy pocos efectos secundarios y raros casos de toxicidad aguda. ${ }^{4}$ 
El metronidazol atraviesa fácilmente la barrera placentaria. ${ }^{5}$ Se ha demostrado que no es teratogénico en animales, aunque es mutagénico para las bacterias y carcinogénico en ratones si se emplea a dosis elevadas y por tiempo prolongado. ${ }^{6}$ No se ha comprobado teratogenicidad o carcinogenicidad en humanos. ${ }^{7}$ Sin embargo, los médicos y las pacientes temen emplear el metronidazol, particularmente durante el primer trimestre de embarazo, prolongando en muchos casos las infecciones del tracto genital inferior y las molestias asociadas a ellas.

Si consideramos que aproximadamente la mitad de los embarazos son no esperados ${ }^{6}$ y que las mujeres sexualmente activas emplean metronidazol con frecuencia, las posibilidades de exposición al medicamento durante el primer trimestre de embarazo resultan ser elevadas. El desconocimiento de la seguridad del medicamento durante la embriogénesis causa gran ansiedad en la mujer y sus familiares ante el temor de tener un hijo con malformaciones congénitas.

El propósito de la presente revisión de la literatura sobre el uso del metronidazol es determinar si existe una relación entre la exposición al metronidazol durante el primer trimestre de embarazo y un mayor riesgo de alteraciones congénitas.

\section{MATERIALES Y MÉTODOS}

Se revisó la literatura sobre el uso del metronidazol en el MEDLine (1990-2001) empleando las palabras claves "embarazo", "metronidazol", "teratogenicidad" (pregnancy-metronidazole, teratogenicity). Se identificaron y revisaron los estudios que hacen referencia al empleo y seguridad del metronidazol durante el primer trimestre de embarazo. También se revisaron las referencias encontradas en estas publicaciones. Para el análisis se seleccionan los estudios que llenan los siguientes criterios: 1) estudio retrospectivo o prospectivo que haga referencia directa al uso del metronidazol durante el primer trimestre de embarazo; 2) inclusión de grupos control de mujeres no expuestas al metronidazol; 3) valoración de los casos de alteraciones congénitas que se hayan presentado en cada uno de estos grupos.

\section{RESULTADOS}

De los trabajos revisados se seleccionaron 6 estudios: dos metanálisis, tres estudios retrospectivos y uno prospectivo (ver tabla 1). El primero de los metanálisis ${ }^{6}$ incluyó 7 estudios (6 prospectivos y 1 retrospectivo) y el segundo, ${ }^{8} 5$ (1 prospectivo y 4 retrospectivos). El número de mujeres expuestas al metronidazol durante el primer trimestre de embarazo varió entre 13 y $13879^{9,10}$ Las alteraciones congénitas observadas han sido presentadas de acuerdo con la tasa de prevalencia o, en la mayor parte de los casos, calculando el factor de riesgo.

El estudio retrospectivo de Piper y cols. ${ }^{10}$ se basa en los registros del Medicaid de Tennessee de los cuales se toman dos grupos similares de mujeres embarazadas que dieron a luz niños sanos o mortinatos entre enero de 1983 y diciembre de 1988. El grupo de casos está conformado por 1387 mujeres a quienes se les prescribió metronidazol 30 días antes de la última menstruación normal o durante el primer trimestre de embarazo. El grupo control está conformado por 1387 mujeres en condiciones similares y a quienes no se les prescribió metronidazol durante el mismo intervalo de tiempo. Al comparar los dos grupos no se encuentran cambios significativos en los patrones de alteraciones congénitas entre las mujeres expuestas y las no expuestas. No se evidencia un mayor riesgo de malformaciones en los hijos de las mujeres expuestas al metronidazol (tasa de riesgo -risk ratio1,2 IC95\% 0,9 a 1,6), ni se evidencia un mayor riesgo para alguna categoría especial de malformaciones. Piper concluye en su estudio que no existe suficiente evidencia que confirme una mayor incidencia de alteraciones congénitas en 
Tabla 1. Resultados de los estudios incluidos en esta revisión

\begin{tabular}{lcccc} 
Estudio & $\begin{array}{c}\text { Grupo } \\
\text { control }\end{array}$ & $\begin{array}{c}\text { Grupo de } \\
\text { casos }\end{array}$ & Tasa de riesgo & $\begin{array}{c}\text { Tasa de } \\
\text { prevalencia }\end{array}$ \\
\hline Piper y cols. & 1387 & 1387 & 1,20 IC95\% 0,90 a-1,60 & - \\
\hline Burtin y cols. & 47649 & 253 & 0,93 IC95\% 0,73 a 1,18 & - \\
\hline Caro-Patón y cols. & - & - & 1,08 IC95\% 0,90 a 1,29 & - \\
\hline Czeizel y cols. & 30663 & 136 & 1,14 IC95\% 0,89 a 1,46 & - \\
\hline Sorensen y cols. & 13327 & 124 & 0,44 IC95\% 0,11 a 1,81 & - \\
\hline Diav-Citrin y cols. & 575 & 190 & - & $1,6 \%$
\end{tabular}

mujeres expuestas al metronidazol durante el primer trimestre de embarazo.

Burtin y colaboradores ${ }^{6}$ revisan la literatura publicada en los últimos 30 años sobre la seguridad del metronidazol durante los primeros meses de embarazo. De 32 estudios que hacen referencia específica al uso del metronidazol durante el embarazo, seleccionan únicamente 7 para el metanálisis, teniendo en cuenta los siguientes criterios: 1) mínimo 10 pacientes expuestas al metronidazol durante el primer trimestre de embarazo; 2) grupo control con un mínimo de 10 pacientes no expuestas al metronidazol o expuestas durante el tercer trimestre de embarazo; 3) informe de las malformaciones observadas en los recién nacidos vivos en cada uno de estos grupos. Seis de estos estudios son prospectivos e incluyen 253 mujeres expuestas al metronidazol durante el primer trimestre de embarazo; el séptimo es retrospectivo e incluye 1083 mujeres expuestas al medicamento durante el mismo período. En sólo 3 de los 7 estudios se describen recién nacidos con alteraciones congénitas y exposición materna al metronidazol durante el primer trimestre de embarazo. Ninguno de ellos detecta un incremento significativo del riesgo de defectos congénitos en los recién nacidos expuestos al metronidazol durante el embarazo porque la tasa de riesgo es baja (tasa de riesgo 0,93 IC95\% 0,73 a 1,18 ) o porque el número de casos es tan pequeño que no se pueden sacar conclusiones. Los autores concluyen que con base en la experiencia de 30 años, no parece que el metronidazol se relacione con un mayor riesgo de teratogenicidad. Se debe emplear en la mujer que lo necesite y a la mujer que lo haya empleado se le debe dar información adecuada para su tranquilidad y para prevenir la injustificada terminación de su embarazo por temor a posibles malformaciones congénitas.

Similar al estudio de Burtin es el que CaroPaton y colaboradores realizan en el Instituto de Farmacoepidemiología de la Universidad de Valladolid, España. ${ }^{8}$ Seleccionaron para el metanálisis todos los estudios epidemiológicos (prospectivos y retrospectivos) que implicaran algún nivel de riesgo de malformaciones congénitas después de la exposición al metronidazol durante los primeros meses de embarazo. Cinco estudios entre todos los revisados llenaron los criterios de inclusión. En ninguno de ellos se detectó un incremento significativo de los defectos congénitos en los hijos de las mujeres expuestas al metronidazol durante el primer trimestre de embarazo (tasa de riesgo 1,08 IC95\% 0,90 a 1,29). El estudio concluye que no existe relación entre la exposición al metronidazol durante el primer trimestre de embarazo y la presencia de malformaciones congénitas. 
En el estudio de Czeizel y Rockenbauer, ${ }^{11}$ se identifican los casos de malformaciones congénitas encontrados en el Registro Húngaro de Alteraciones Congénitas durante los años 19801991 y se comparan con los controles sanos nacidos de mujeres expuestas al metronidazol durante el embarazo. El grupo de control incluye 30663 mujeres con hijos sanos y el grupo de casos, 17300 mujeres con hijos que presentaron alguna malformación de tipo congénito. De las 30.663 mujeres del grupo control, $1041(3,4 \%)$ recibieron tratamiento con metronidazol durante su embarazo, y de estas 186 lo hicieron durante el primer trimestre. En el grupo de casos (17 300), 665 (3,8\%) mujeres fueron tratadas con metronidazol, 136 durante el primer trimestre de embarazo. Para el análisis se consideran cuatro períodos gestacionales: a) primer mes de embarazo considerado como una continuación del tratamiento antes de la concepción; b) segundo y tercer meses de gestación considerados como el período crítico y más sensible a la presencia de alteraciones congénitas; c) del cuarto al noveno mes de gestación y d) mujeres embarazadas expuestas al metronidazol sin precisar el momento en que se produjo la exposición. Se agrupan las malformaciones congénitas observadas relacionándolas con cada uno de los 4 períodos gestacionales establecidos y se determina la tasa de riesgo para cada una de ellas. Concluyen que el tratamiento con metronidazol durante el embarazo no presenta ninguna asociación clínica importante con las malformaciones congénitas y por lo mismo puede emplearse sin temor, por parte del médico o de la paciente, gracias a su no comprobada teratogenicidad.

Sorensen y colaboradores ${ }^{12}$ realizan un estudio de cohorte en el condado de North Jutland, Dinamarca con el fin de comparar la prevalencia de anormalidades congénitas, bajo peso al nacer y parto prematuro en mujeres expuestas al metronidazol durante su embarazo. Utilizando los registros oficiales identifican 124 mujeres expues- tas al metronidazol durante el embarazo, 13327 no expuestas (controles) y las alteraciones congénitas que de acuerdo con las normas locales se diagnosticaron inmediatamente después del parto. Establecen dos grupos de estudio teniendo en cuenta el momento de la exposición al metronidazol: 1) primer trimestre de embarazo para analizar el riesgo de alteraciones congénitas y 2) segundo y tercer trimestres de embarazo para analizar el bajo peso al nacer y la prevalencia de partos prematuros. No se observó incremento en el riesgo de alteraciones congénitas en el grupo de mujeres expuestas al metronidazol durante el primer trimestre de embarazo (tasa de riesgo 0,44, IC95\% 0,11 a 1,81). Concluye el estudio que no existe un incremento en el riesgo de malformaciones congénitas entre las mujeres expuestas al metronidazol y que, aunque no es fácil demostrar la no teratogenicidad del metronidazol, los datos disponibles muestran plenamente que no hay mayor riesgo.

Recientemente el Servicio Israelí de Información sobre Teratogenicidad ${ }^{13}$ ha seleccionado prospectivamente y hecho seguimiento a $228 \mathrm{mu}-$ jeres expuestas al metronidazol durante el embarazo, de las cuales $86,2 \%$ lo estuvieron durante el primer trimestre. El curso del embarazo de estas mujeres fue comparado con el de un grupo control no expuesto al metronidazol. No se observa diferencia mayor en la tasa de malformaciones entre los dos grupos: 3/190 (1,6\%) para el grupo expuesto al metronidazol y $8 / 575$ (1,4\%) para el grupo control. La tasa de malformaciones mayores tampoco difiere entre los dos grupos inclusive cuando se incluyen los casos en que se practicó un aborto electivo indicado al diagnosticar las malformaciones durante el embarazo: 5/192 (2,6\%) para el grupo expuesto al metronidazol y $12 / 579$ $(2,1 \%)$ para el grupo control. Este estudio, de acuerdo a los autores, confirma que el metronidazol no representa un riesgo teratogénico para el humano cuando se emplea a dosis terapéuticas. 


\section{COMENTARIOS}

La revisión de Burtin es, sin duda alguna, la más completa que se tiene sobre el empleo del metronidazol durante el embarazo. Revisa toda la literatura médica sobre metronidazol, embarazo y teratogenicidad desde la aprobación del metronidazol en 1959. Como un buen número de estos estudios fue publicado antes de 1966, fecha en que se inició el Medline, la investigación se completó revisando sistemáticamente todas las referencias encontradas en los artículos publicados posteriormente. En solamente 3 de los 7 estudios seleccionados por Burtin para el metanálisis se encuentran casos de alteraciones congénitas en el grupo expuesto al metronidazol durante el primer trimestre de embarazo. La tasa de riesgo para estos estudios varía entre 0 y 2,15. Ninguna de estas tasas de riesgo es significativa estadísticamente (el 95\% de los límites de confianza incluyen 1,0) y ninguna de ellas detecta un incremento de riesgo de alteraciones congénitas en los niños expuestos al metronidazol durante el primer trimestre de embarazo. En los 25 estudios no incluidos en el metanálisis se describen 3 casos de defectos faciales de la línea media que podrían relacionarse con la exposición de las madres al metronidazol durante la quinta y séptima semanas de gestación. ${ }^{14-15}$ Esta relación, sin embargo, no ha sido comprobada por ningún otro estudio y podría atribuirse probablemente a la casualidad. ${ }^{6}$

El trabajo de Czeizel es particularmente ilustrativo porque presenta los casos de alteraciones congénitas comparándolos con controles sanos nacidos de mujeres expuestas al metronidazol durante el embarazo. Los resultados parecen coincidir, según afirma el mismo Czeizel, con los del metanálisis de Burtin. Encuentra, sin embargo, que la tasa de riesgo del metronidazol empleado durante el primer trimestre de embarazo es más elevada en el grupo de casos de labio leporino con o sin paladar hendido, sin que esto implique una asociación clínica importante entre el uso del metronidazol en los primeros meses de embarazo y las incidencia de alteraciones congénitas.

Los hallazgos encontrados en los otros estudios son similares a los encontrados en los anteriores. La tasa de riesgo entre las mujeres expuestas y las no expuestas durante el primer trimestre de embarazo fluctúan entre 0,44 (IC95\% 0,11 a 1,81) en el estudio de Sorensen en Dinamarca y 1,08 (IC95\% 0,90 a 1,29) en el metanálisis de Caro-Paton en España. Estas tasas, definitivamente no revelan un incremento en el riesgo de malformaciones congénitas entre las mujeres expuestas al metronidazol durante los primeros meses de embarazo.

Los resultados de estos estudios nos llevan a concluir que el metronidazol no parece estar asociado a un mayor riesgo de teratogenicidad cuando se emplea durante el primer trimestre de embarazo. Los pocos casos en que se han observado alteraciones congénitas después de la exposición al metronidazol durante el embarazo son aislados, no han sido comprobados y podrían atribuirse a la simple casualidad. El metronidazol puede y debe emplearse en las situaciones en que esté indicado, independientemente de si la mujer está o no está embarazada. En situaciones especiales la administración vaginal es una excelente y efectiva alternativa a la administración oral. Los niveles plasmáticos de metronidazol son inferiores cuando se administra por vía vaginal. ${ }^{16,17}$ Finalmente, a las mujeres embarazadas que han estado expuestas al metronidazol, incluyendo el primer trimestre de embarazo, se les debe dar a conocer que, de acuerdo con estos estudios, no deben angustiarse ante la posibilidad de tener un hijo con malformaciones congénitas y mucho menos pensar en que deben interrumpir su embarazo.

\section{REFERENCIAS}

1. Schwebke JR. Metronidazole: utilization in the obstetric and gynecologic patient. Sex Transm Dis 1995;22(6):370-6 
2. Lossick JG, Kent HL. Trichomoniasis: trends in diagnosis and management. Am J Obstet Gynecol 1991;165:1217-22.

3. Joesoef MR, Schmid GP, Hillier SL. Bacterial vaginosis: review of treatment options and potential clinical indications for therapy. Clin Infect Dis 1999;28 Suppl 1:357-65.

4. AMA Drug Evaluations, Annual 1994, AMA. Philadelphia: WC Saunders Company. 1994.

5. Heisterberg L. Placental transfer of metronidazole in the first trimester of pregnancy. J Perinat Med $1984 ; 12: 43-5$.

6. Burtin P, Taddio A, Aribumu O, Einarson TR, Koren G. Safety of megtronidazole in pregnancy: a metaanalysis. Am J Obstet and Gynecol 1995; 172:52529

7. Beard CM,Noller KL, O'Fallon M, Kurland LT, Dockerty MB. Lack of evidence for cancer due to use of metronidazole. N Engl J Med 1979;301:51922.

8. Caro-Paton T, Carvajal A, Martín de Diego I, MartínArias LH, Alvarez Requejo A, Rodríguez Pinilla E. Is metronidazole teratogenic? A meta-analysis. $\mathrm{Br} J$ Clin Pharmacol 1997, 44(2): 179.

9. Scott-Gray M. Metronidazole in obstetric practice. Obstet Gynecol 1964;71:82-5.

10.Piper JM, Mitchel EF, Ray WA. Prenatal use of metronidazole and birth defects: no association. Obstet Gynecol 1993;82:348-52.
11.Czeizel AE, Rockenbauer M. A population based casecontrol teratologic study of oral metronidazole treatment during pregnancy. Br J Obstet Gynaecol 1998;105:322-327.

12. Sorensen HT, Lrsen H, Jensen ES, Thulstrup AM, Schonheyder HC, Nielsen GL, Czeizel. Safety of metronidazole during pregnncy: a cohort study of risk of congenital abnormalities, preterm delivery and low birth wight in 124 women. J Antimicrob Chemother 1999;44:854-855.

13.Diav-Citrin O, Shechtman S, Gotteiner T, Arnon J, Ornoy A. Pregnancy outcome after gestatinal exposure to metronidazole: a prospective contolled cohor study. Teratology 2001;63(5):186-192.

14. Cantu JM, García-Cruz D. Midlinefacial defect as a teratogenic effect of metronidazole. Birth Defects $1982 ; 18: 85-8$

15. Greenberg F. Possible metronidazole teratogenicity and clefting. Am J Med Genet 1985;22:825.

16. Schwebke JR. Metronidazole: Utilization in the Obstetric and Gynecologic Patient. Sexually Transm Diseases 1995;22:370-376.

17. Alper MM, Barwin BN, McLean WM, McGilveray IJ, Sved S. Systemic absorption of metronidazole by the vaginal route. Obstet Gynecol 1985;65:781-784. 